\title{
Satellite image analysis and archaeological fieldwork in El-Markha Plain (South Sinai)
}

\author{
Gregory Mumford \& SARah ParcaK*
}

The application of satellite image analysis to archaeology is well known (Kennedy 1997: 71-93), but it is less frequently applied to the location of potential archaeological sites. The South Sinai Survey and Excavation Project, directed by GM, incorporates both surface survey work and the application of multiple analytical techniques to satellite images (e.g. a Landsat TM image) to detect new and already identified archaeological sites in El-Markha Plain, along the west Sinai coast (FIGURES $1 \& 2$ ). The northern end of El-Markha Plain contains a natural port (Markha Bay) and straddles the primary north-south, overland route through which ancient Egyptian expeditions traveled to reach the turquoise and copper mines in South Sinai (Mumford 1999: 722-5 and 875-8).

In 1948 W.F. Albright discovered a New Kingdom coastal site (no. 346) at the northern end of El-Markha Plain. The site measured 50×110 m and rose $1 \mathrm{~m}$ above the plain. Road construction subsequently destroyed its western side, leaving a 40x50-m area. The University of Toronto project visited this site in the summer of 2000 and 2001, observing New Kingdom pottery, copper slag, lithics, grinding stones and pounders, while surface surveys revealed two new sites (pottery scatters) beside two wadis to the south. The 2002 excavations at Site $\mathbf{3 4 6}$ revealed copper smelting furnaces and New Kingdom and Roman pottery. The project also investigated nearby Site 345 (found in 1967 by $B$. Rothenberg), which revealed a 40$\mathrm{m}$ wide, circular limestone fort with late Roman and Islamic pottery.

Despite the obvious benefits of direct ground surveys, the large area of and numerous fenced petroleum compounds within El-Markha Plain require new approaches to identifying potential archaeological sites. However, while many archaeological features (i.e. ancient tells and caravan routes) are visible from space, El-Markha Plain contains small, low-lying archaeological and natural mounds that are often hard to distinguish from one another and the surrounding landscape. Archaeological surveys within other coastal regions (e.g. Israel) reveal higher concentrations of vege-

tation at ancient sites owing to the artificial introduction of organic and inorganic materials and architectural anchorages for plants. Such vegetation also indicates the presence of water, one of the primary requirements for human settlements. Hence, the application of Normalized Difference Vegetation Index (NDVI) to satellite images of deserts, such as El-Markha Plain, promised to reveal ancient sites in a time- and cost-effective manner.

This technique was applied to the satellite image encompassing Site 346 . The environs of the site yielded a positive NDVI (FIGURE 3), indicating adjacent vegetation and thereby water sources. In contrast, most of the El-Markha Plain satellite image produced negative NDVI values, reflecting the drier plain and coastline (FIGURE 4). Although both the image (taken in August) and ground-truthing results represented the driest summer months, the satellite image did yield three positive NDVI values and 27 near-positive values within the plain, demonstrating that significant sub-surface moisture remained to support vegetation. The satellite image and 30 NDVI signatures required analytical assessment through 'supervised', 'unsupervised' and thresholding classifications (Jensen 1996: 197-252) to test the veracity of the initial results. Supervised classification proved unsuccessful since the available satellite image contained insufficient pixels with positive NDVI values to classify the different types of regions in the image. From an original 30 signatures, the application of unsupervised classification produced 20 NDVI areas with similar values. The most successful t e c h n i q u e, thresholding, included a specific formula ('If

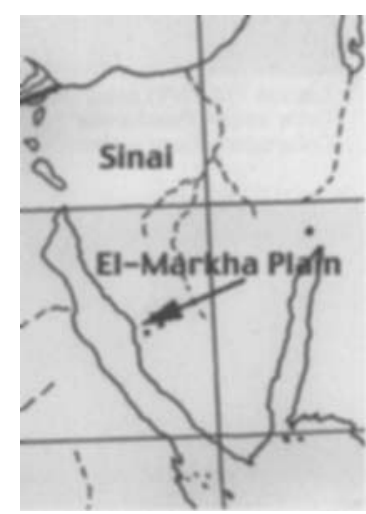

FIGURE 1. Map of Sinai.

\footnotetext{
* Mumford, Department of Near \& Middle Eastern Languages \& Civilizations, University of Toronto, 4 Bancroft Avenue, Toronto ONT, Canada M5S 1C1. gregorymumford@hotmail.com Parcak, Department of Archaeology, Cambridge University, Downing Street, Cambridge CB2 3Dz, England. sp313@cam.ac.uk
} 

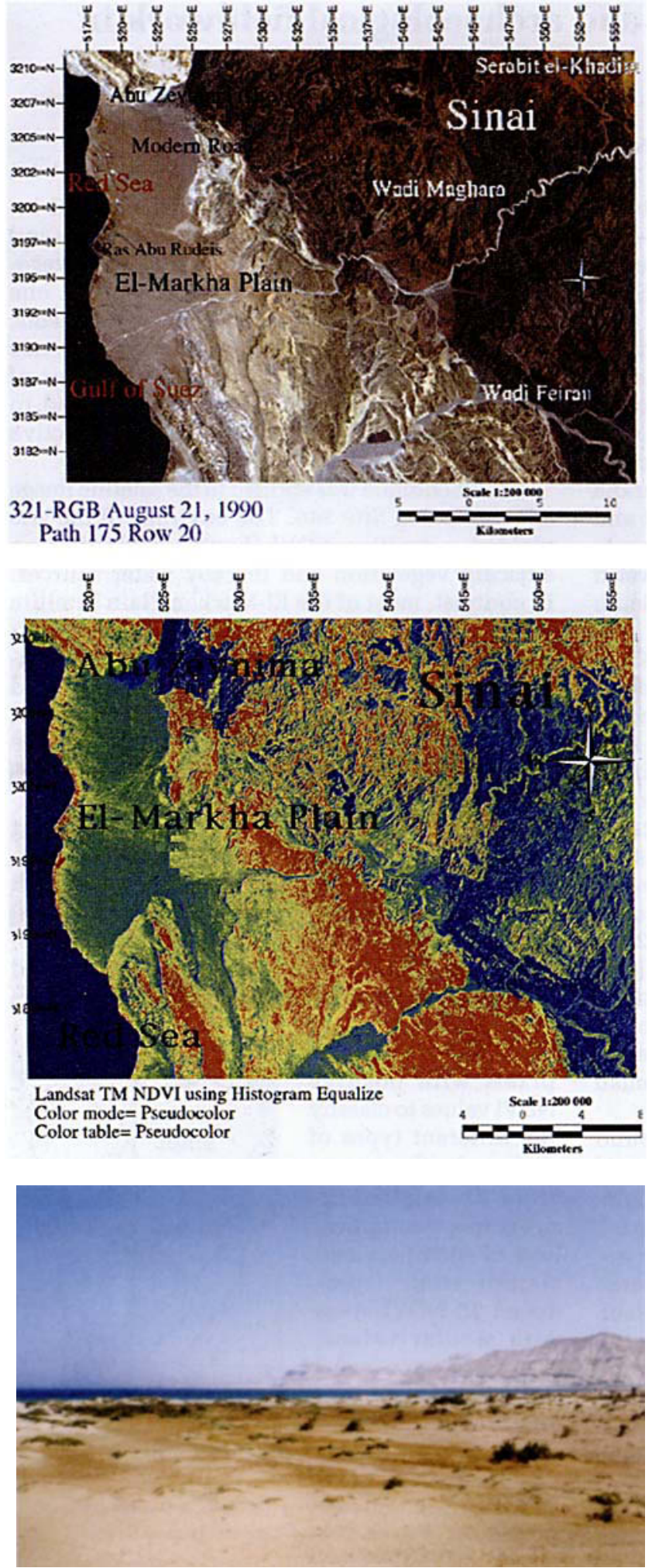

input 1 is greater than -0.05 else null') to remove all areas with NDVI values less than -0.05 from the satellite image. The resulting 16 signatures included five positive NDVI values, two NDVI value of 0 , and nine slightly negative NDVI values, in contrast to much lower values for the remaining plain.

Preliminary survey work reveals that archaeological sites in El-Markha Plain appear beside vegetation areas (i.e. water sources), wadi beds and the bases of hills bordering the plain's eastern edge. Although many of the apparent NDVI signatures actually represent modern vegetation and palm groves, new archaeological sites were detected around the edges of these areas. Site 346 lies beside a protected anchorage and wadi bed (with water in winter). Future satellite image analysis with finer pixel resolutions should reveal more sites and will clarify the ancient routes to the copper and turquoise mines in South Sinai.

Acknowledgements. Special thanks go to Larry Bonneau, Yale University, for advice and suggestions. Additional thanks go to the Supreme Council for Antiquities in Egypt, the American Research Center in Egypt, the University of Toronto and the Social Sciences \& Humanities Research Council of Canada for their support of the South Sinai Survey and Excavation Project.

\section{References}

JENSEN, J. 1996. Introductory digital image processing: a remote sensing perspective. Upper Saddle River (NJ): Prentice Hall.

KENNEDY , D. 1997. Roman roads and routes in northeast Jordan, Levant 29: 71-93.

MuMFord, G.D. 1999. Serabit el-Khadim and Wadi Maghara, in K.A. Bard (ed.), Encyclopedia of the archaeology of Ancient Egypt. New York (NY): Routledge.

FIGURE 2 (top). Landsat image.

FIGURE 3 (middle). Landsat TM NDVI image: red areas along the coast include 30 sites.

FIGURE 4 (bottom). Photograph of ElMarkha Plain. 